\title{
Detection of recurrent breast carcinoma using unenhanced breast MRI
}

\author{
Mohamed Ali EL-Adalany and Dina EL-Metwally*
}

\begin{abstract}
Background: Early detection of locally recurrent breast carcinoma has been shown to significantly improve longterm survival. Surgery and radiation therapy made treated breast prone to several modifications. This can complicate the interpretation of ultrasound and mammographic images, especially when local recurrence is suspected. The aim of this work is to assess the role of unenhanced MRI (T1WI, T2WI, STIR, and DWI) in differentiating recurrent breast cancer from benign post-operative lesions.

Results: The presence of fat SI within the lesions had 100\% sensitivity, 90.9\% specificity, 94.1\% PPV, 100\% NPV, and 96.2\% accuracy in differentiating fat necrosis from recurrent breast carcinoma. A cutoff ADC value of $1 \times 10-3 \mathrm{~mm}^{2} /$ s for observer one had $80 \%$ sensitivity, $90.9 \%$ specificity, and $88.9 \%$ accuracy in diagnosis of recurrent breast carcinoma. For observer two, a cutoff ADC value of $1.25 \times 10-3 \mathrm{~mm} 2 / \mathrm{s}$ had sensitivity of $80 \%$, specificity of $88.6 \%$, and diagnostic accuracy of $87.03 \%$ in differentiating recurrent breast carcinoma from benign post-operative changes. Unenhanced MRI had $81.8 \%$ sensitivity, 97.7\% specificity, 90\% PPV, 95.5\% NPV, and $94.5 \%$ accuracy in the diagnosis of recurrent breast carcinoma.

Conclusion: Unenhanced MRI including T1WI, T2WI, STIR, DWI, and ADC map had high sensitivity, specificity, and diagnostic accuracy in diagnosis of recurrent breast carcinoma and differentiating it from benign post-operative changes.
\end{abstract}

Keywords: Unenhanced MRI, Recurrent breast carcinoma, Benign post-operative changes, DWI, ADC, T1WI

\section{Background}

After breast conservative therapy, the incidence of ipsilateral recurrent breast carcinoma is about $1 \%$ per year for invasive breast cancer and is slightly less for ductal carcinoma in situ (DCIS). Women who are at the greatest risk for recurrence are those who are younger than 35 years, patients with high-grade DCIS, patients with DCIS measuring $>2.5 \mathrm{~cm}$ in diameter, patients with invasive ductal carcinoma with a large DCIS component, and patients with multifocal breast carcinoma [1]. Early detection of locally recurrent breast carcinoma has been shown to significantly improve long-term survival [2].

Surgery and radiation therapy made treated breast prone to several modifications. This can complicate the

\footnotetext{
* Correspondence: elmetwallydina@gmail.com

Faculty of Medicine, Mansoura university, Mansoura, Egypt
}

interpretation of ultrasound and mammographic images, especially when local recurrence is suspected [3].

Dynamic contrast-enhanced magnetic resonance imaging (DCE-MRI) has been shown to be a valuable tool in detection and characterization of primary and recurrent breast carcinoma [4]. The sensitivity of breast MRI for detection of recurrent breast carcinoma in the post-breast conservative surgery is more than 90\% [2]. DCE-MRI has been shown to be useful in differentiating post-operative scar from recurrent breast carcinoma, whereas non-enhancing lesions usually represent postoperative scar rather than recurrent breast carcinoma [5].

The ability of DCE-MRI to differentiate between recurrent breast carcinoma and benign post treatment changes depends on its ability to assess both lesion morphology and enhancement kinetics [6].

(c) The Author(s). 2020 Open Access This article is licensed under a Creative Commons Attribution 4.0 International License, which permits use, sharing, adaptation, distribution and reproduction in any medium or format, as long as you give appropriate credit to the original author(s) and the source, provide a link to the Creative Commons licence, and indicate if changes were made. The images or other third party material in this article are included in the article's Creative Commons licence, unless indicated otherwise in a credit line to the material. If material is not included in the article's Creative Commons licence and your intended use is not permitted by statutory regulation or exceeds the permitted use, you will need to obtain permission directly from the copyright holder. To view a copy of this licence, visit http://creativecommons.org/licenses/by/4.0/. 
However, contrast-enhanced breast MRI has many side effects as the high economic cost of the used contrast media. Also, it is contraindicated in patients with impaired renal function [7].

Traditional unenhanced sequences, primarily T2weighted fast spin-echo and STIR, received new attention in terms of diagnostic signs. In addition, the use of diffusion-weighted imaging (DWI) was proposed for breast MRI, mainly for lesion characterization using the apparent diffusion coefficient (ADC) as a quantitative approach to differentiate benign from malignant lesions [7]. High cellularity in breast cancers causes barriers to the extracellular water diffusion, and this result in signal loss and low ADC values [8]. On the basis of these criteria, DWI can offer an unenhanced tool to detect breast carcinoma without the costs and safety concerns associated with DCE-MRI [9].

Also, T1-weighted sequence is highly important in diagnosis of post-operative fat necrosis which is a common complication following breast surgery and radiation therapy. The presence of fat signal in a lesion revealed sensitivity of $98.04 \%$, specificity of $100 \%$, PPV of $100 \%$, and NPP of $96.88 \%$ for diagnosis of fat necrosis [10].

\section{Aim of the study}

The purpose of this study was to assess the role of unenhanced MRI including T1WI, T2WI, STIR image, and DWI in differentiation between recurrent breast cancer and benign post-operative lesions (e.g., fat necrosis) taking the results of histopathology as our standard of reference.

\section{Methods}

\section{Patient's demographic data}

This prospective study was performed on 110 female patients with history of breast cancer and underwent operation either conservative breast surgery (86 patients) (78.2\%) or modified radical mastectomy (MRM) (24 patients) (21.8\%). Their age ranged from 34 to 60 years with a mean $\pm \mathrm{SD}=47.23 \pm 7.10$. It was performed during the period from January 2018 till December 2019 and was approved by our institution's ethics committee. All patients gave their informed consent before inclusion in the study.

\section{Inclusion criteria}

Female patients with history of breast cancer and underwent surgery for treatment of breast cancer and referred for MRI with suspicion to have local regional recurrence on the basis of clinical examinations (e.g., palpable mass or an irregular area of firmness at the operative bed, skin changes, skin inflammation or area of redness, one or more painless nodules on or under the skin of the chest wall in cases of MRM, or thickening along or near the mastectomy scar) or on the basis of sonomammographic examination (e.g., areas of parenchymal distortion, irregular shaped masses with skin retraction, and hypoechoic masses with posterior shadowing).

\section{Exclusion criteria}

Patients who have contraindications to do MRI as patients with cardiac pace maker, patients with cochlear implant and ocular foreign body, patients on neoadjuvant chemotherapy, and patients who performed unplanned excision of breast cancer.

\section{MRI technique}

MRI was performed on $1.5 \mathrm{~T}$ MR imaging unit (Philips Ingenia). All patients were examined in the prone position using dedicated breast coil. All patients underwent the following: FSE axial non-fat saturated TIWI (TR 450 $\mathrm{ms}$ and $\mathrm{TE} 14 \mathrm{~ms}$ ), axial non-fat-suppressed T2weighted turbo spin-echo (TR $4500 \mathrm{~ms}$ and TE $97 \mathrm{~ms}$ ), and axial STIR images (TR 7000-9000 ms, TE $70 \mathrm{ms,}$ and inversion time (TI) was $150 \mathrm{~ms}$ ).

DWI was obtained before contrast medium injection using a multislice, single-shot, spin-echo, echo-planar image sequence. A set of multiple axial scans of the breast was obtained. The scanning parameters were TR/ $\mathrm{TE}=10.000: 108 \mathrm{~ms}, \mathrm{NEX}=8-16$, bandwidth $=300 \mathrm{kHz}$, FOV $=300-360 \mathrm{~mm}$, slice thickness was $4 \mathrm{~mm}$, and acquisition matrix $=256 \times 128$. The diffusion gradients were applied in three orthogonal directions $(\mathrm{x}, \mathrm{y}$, and $\mathrm{z})$. Diffusion-weighted MR images were acquired with $\mathrm{b}$ factor of 0 or 500 and $1000 \mathrm{~s} / \mathrm{mm}^{2}$, and ADC maps were reconstructed.

DCE-MRI was performed after injection of a bolus of gadopentetate dimeglumine, in a dose of $0.2 \mathrm{~m}-\mathrm{mol} / \mathrm{kg}$ using an automated injector at a rate of $3-5 \mathrm{ml} / \mathrm{s}$. This was followed by a bolus injection of saline (a total of 20 $\mathrm{ml}$ at $3-5 \mathrm{ml} / \mathrm{s}$ ). Dynamic images were obtained in the axial plane with fat suppression. The sequence used was FLASH 3-D GRE-T1WI with the following parameters: TR 4-8 ms, TE $2 \mathrm{~ms}$, flip angle 20-25, slice thickness 2 $\mathrm{mm}$ with no inter-slice gap, FOV $300-360 \mathrm{~mm}$, and the matrix was $307 \times 512$. Dynamic study consists of one pre-contrast and 5 postcontrast series. Subtraction images were obtained by subtracting each of the precontrast images from each post-contrast series images.

\section{Image interpretation}

Two experienced radiologists blinded to each other and blinded to the results of histopathological examinations evaluated the MRI images for the following:

1) Signal intensity of the lesion on non-contrast images (T1WI, T2WI, and STIR). 


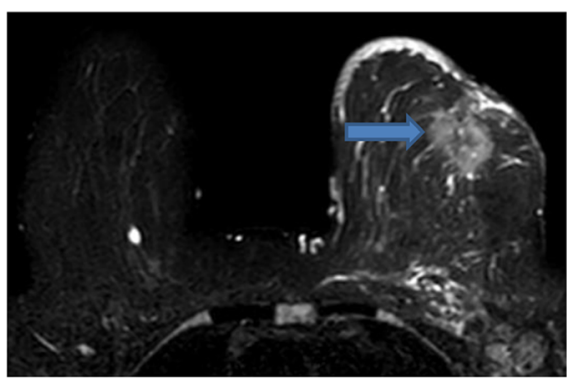

(A)

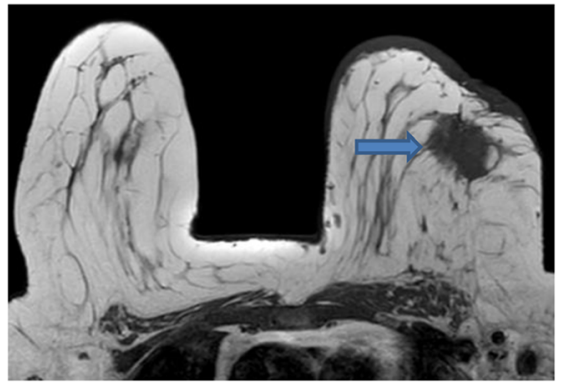

(B)

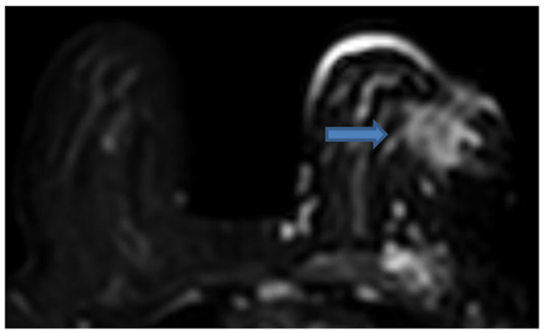

(C)

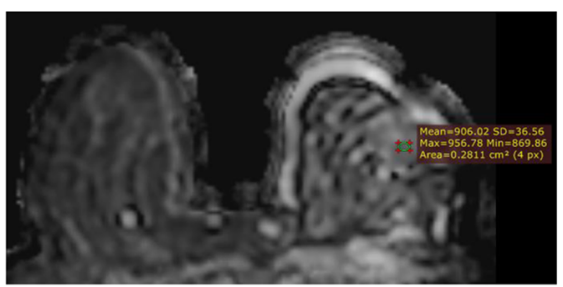

(D)

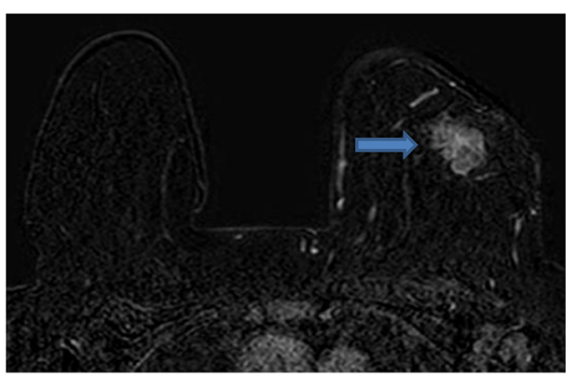

(E)
Fig. 1 Female patient aged 50 years with history of left breast cancer underwent conservative breast surgery and then presented by palpable left breast mass. a Axial STIR image showed retroareolar lesion of intermediate signal intensity. $\mathbf{b}$ Axial T1WI, the lesion appeared of low signal intensity. $\mathbf{c}, \mathbf{d}$ DWI and ADC map, the lesion appeared restricted with a mean $A D C$ value $=0.9 \times 10-3 \mathrm{~mm}^{2} / \mathrm{s}$. e Subtraction MR image showed heterogeneously enhancing irregular shaped retroareolar mass. Pathological diagnosis revealed recurrent grade II invasive duct carcinoma

2) As regard to diffusion images, there were two methods for evaluation: (A) qualitative analysis of DWI was performed by a combined visual assessment of the high $b$ value DWI ( $b$ 1000) and the corresponding ADC maps. Recurrent breast carcinoma appeared high SI on the high $b$ value DWI and of low SI on ADC maps. Benign post-operative breast lesions (post-operative scar, fat necrosis, and post-operative seroma) are characterized by low SI on high the $b$ value DWI and high SI on ADC map. Sometimes, postoperative seroma appeared of high SI on both DWI and ADC map, and this is termed T2 shine through artifact (decreased on high $b$ value image). (B) Quantitative analysis of DWI was performed by calculating the ADC values of tissues. An ROI is manually drawn along the margins of the lesion on ADC map images.

On the basis of non-contrast MR images and diffusion images, recurrent breast carcinoma was diagnosed when the lesion appeared of low signal intensity on T2WI, low signal intensity on T1WI, and show restricted diffusion with low ADC value (Fig. 1). Post-operative fat necrosis was diagnosed when the lesion showed fat signal intensity (high signal intensity on T1WI and low signal intensity on STIR images compared with the surrounding breast fat) and appeared free on diffusion with high ADC value (Fig. 2). Post-operative seroma was diagnosed when the lesion appeared of high signal intensity on T2WI and STIR images, low signal intensity on T1WI, and appeared free on diffusion with high ADC value (Fig. 3). Postoperative scar was diagnosed when the lesion appeared of intermediate signal intensity on T2WI, low signal intensity on T1WI, and free on diffusion with high ADC value (Fig. 4). We did not depend on the assessment of lesion shape and margins to differentiate between benign post-operative changes and recurrent breast carcinoma as post-operative scar, and fat necrosis usually has irregular shape and margins so could not be discriminated from recurrent breast carcinoma on the basis of lesion shape and margins. 


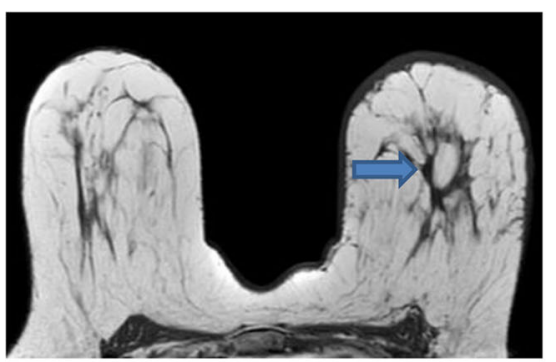

(A)

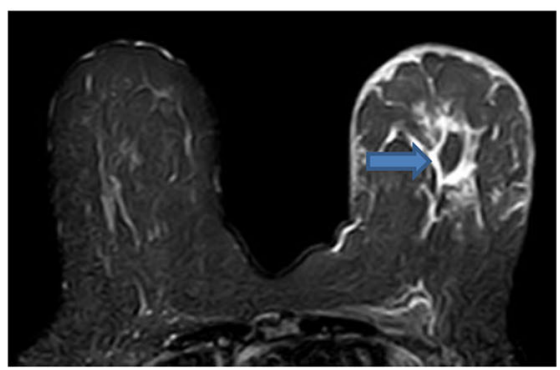

(B)

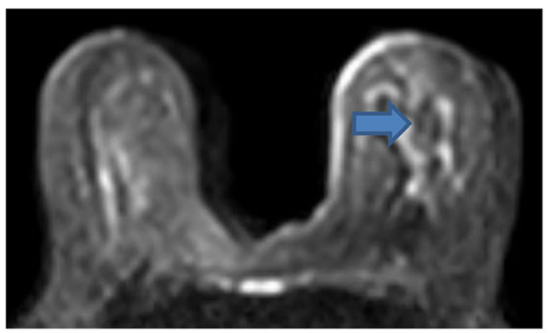

(C)

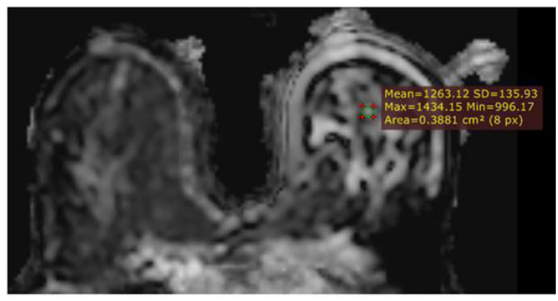

(D)

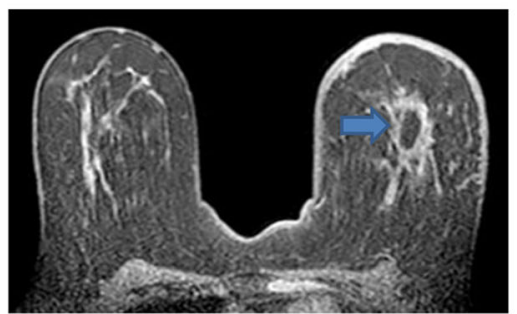

(E)
Fig. 2 Female patient aged 38 years with history of left breast cancer underwent conservative breast and then presented by palpable lump. a Axial T1WI showed lesion of high signal intensity in the left breast. $\mathbf{b}$ Axial STIR image, the lesion appeared of low signal intensity. c, $\mathbf{d}$ DWI and ADC map, the lesion appeared free on diffusion with a mean $A D C$ value $=1.29 \times 10-3 \mathrm{~mm}^{2} / \mathrm{s}$. e Dynamic MR image showed marginally enhanced oval shaped lesion in the left breast. Pathological diagnosis revealed fat necrosis

\section{Final diagnosis}

The results of histopathological examinations were considered as our standard of reference. The interval between the MRI examination and the histopathological examination was 10-15 days. When patients were suspected to have recurrent breast carcinoma, postoperative scar or fat necrosis on the basis of MRI, Trucut biopsy was done using 14-16 gauge core needle. When patients were suspected to have post-operative seroma on the basis of MRI, FNAC was performed to exclude presence of malignant cells.

\section{Statistical analysis}

Data was analyzed using the Statistical Package for Social Science software computer program version 23 (SPSS, Inc., Chicago, IL, USA). Data were expressed as mean \pm SD (standard deviation) for quantitative parametric data and as frequency (number-percent) for qualitative data. Kappa agreement was used for interrater agreement. The intraclass correlation coefficient (ICC) was used as a measure of inter-rater agreement for continuous scales. Sensitivity, specificity, PPV (positive predictive value), NPV (negative predictive value), and accuracy were calculated to differentiate between benign post-operative lesions and recurrent breast carcinoma by unenhanced MRI. The sensitivity and specificity of ADC to differentiate between benign and malignant lesions were examined at different cutoff points using ROC curve analysis to determine the best cutoff point as well as the diagnostic power of each test. $P$ value less than 0.05 was considered statistically significant.

\section{Results}

The final pathological diagnosis of 110 patients was recurrent breast carcinoma (grade II invasive duct carcinoma) in 22 patients (20\%), fat necrosis in 32 patients (29\%), post-operative seroma in 46 patients (41.8\%), post-operative scar in 8 patients (7.2\%), and infected seroma in 2 patients (1.8\%).

On this study, we depended on the analysis of signal intensity of lesions on non-contrast images and the measured ADC values to differentiate between benign postoperative changes and recurrent breast carcinoma. 


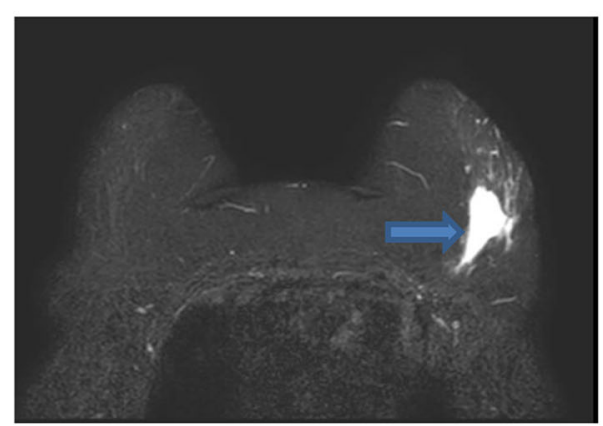

(A)

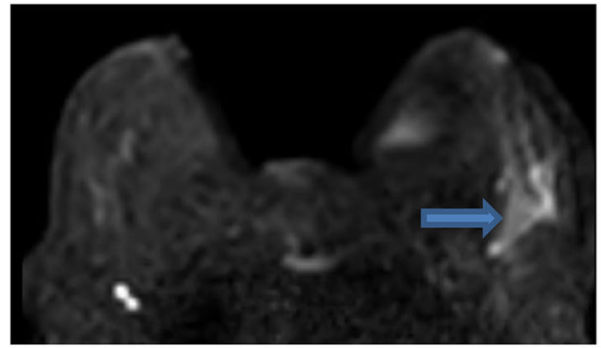

(C)

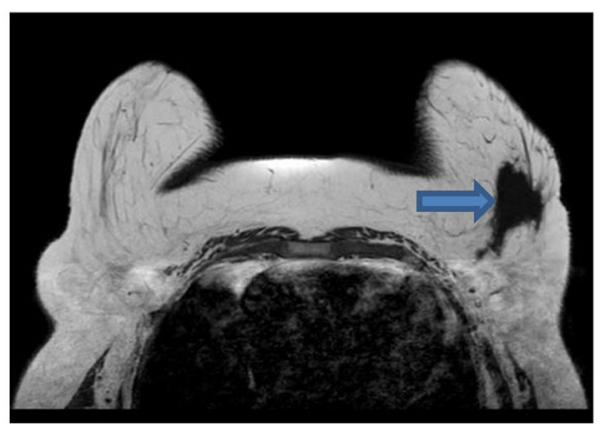

(B)

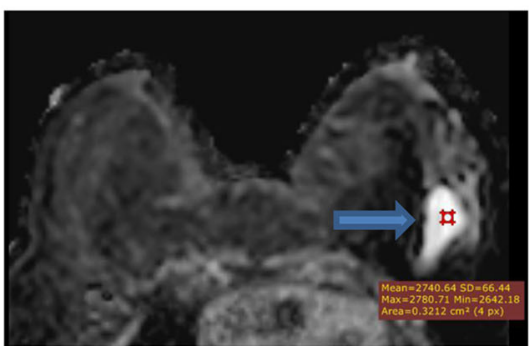

(D)

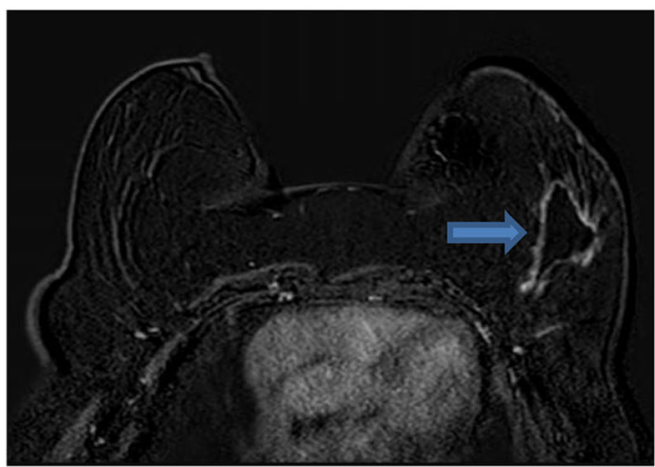

(E)

Fig. 3 Female patient aged 51 years with history of left breast cancer underwent conservative breast surgery and then presented by palpable left breast mass. a Axial STIR image showed lesion of high signal intensity. $\mathbf{b}$ Axial T1WI, the lesion appeared of low signal intensity. $\mathbf{c}$, $\mathbf{d}$ DWI and $A D C$ map, the lesion appeared free on diffusion with a mean $A D C$ value $=2.5 \times 10-3 \mathrm{~mm}^{2} / \mathrm{s}$. e Subtraction MR Image, the lesion, showed thin smooth marginal enhancement. FNAC show post-operative seroma with no malignant cells detected

Regarding the presence of fat signal intensity within the lesions, both observers found that fat SI was found in all cases of fat necrosis included in this study and in only two cases of recurrent breast carcinoma included in this study. The presence of fat SI within the lesions had $100 \%$ sensitivity, $90.9 \%$ specificity, 94.1\% PPV, 100\% NPV, and 96.2\% accuracy in differentiating fat necrosis from recurrent breast carcinoma (Table 1).
On measuring ADC value for the 110 patients, observer one found that the mean $\mathrm{ADC}$ value for recurrent breast carcinoma was $0.79 \times 10-3 \mathrm{~mm}^{2} / \mathrm{s}$, mean ADC value for fat necrosis was $1.39 \times 10-3 \mathrm{~mm}^{2} / \mathrm{s}$, mean ADC value for post-operative seroma was $2.37 \times 10-3$ $\mathrm{mm}^{2} / \mathrm{s}$, mean ADC value for post-operative scar was $1.73 \times 10-3 \mathrm{~mm}^{2} / \mathrm{s}$, and mean ADC value for infected seroma was $0.9 \times 10-3 \mathrm{~mm}^{2} / \mathrm{s}$. Observer two found that the mean ADC value for recurrent breast carcinoma was 


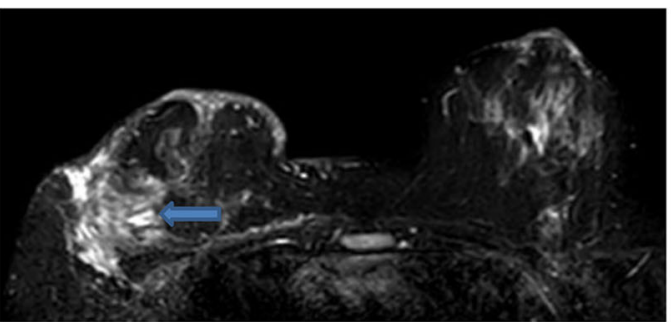

(A)

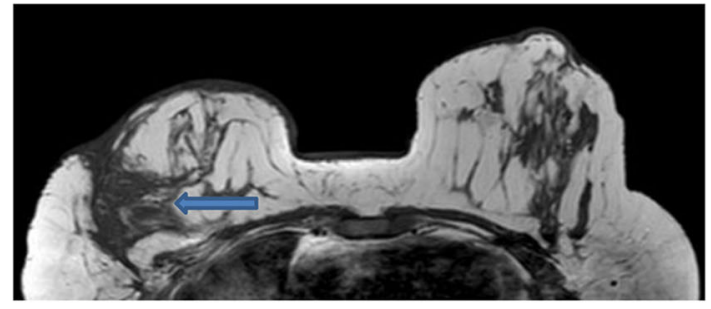

(B)

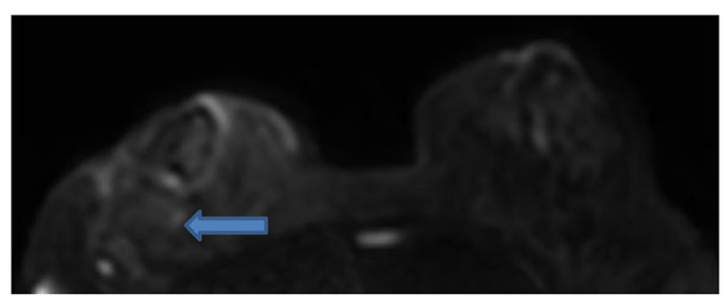

(C)

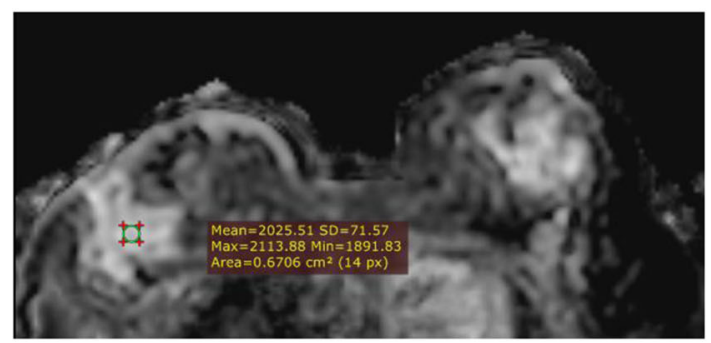

(D)

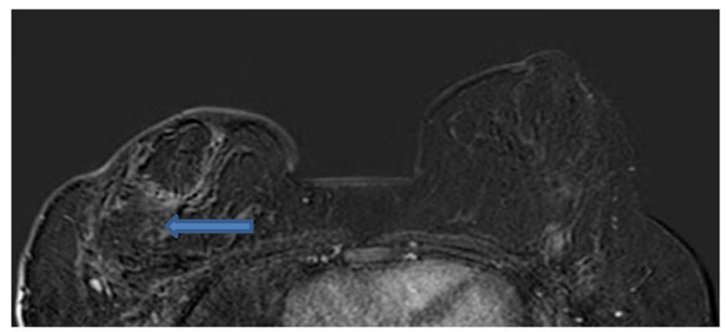

(E)
Fig. 4 Female patient aged 36 years with history of right breast cancer underwent conservative breast surgery and then presented by palpable right breast mass. a Axial STIR image showed irregular shaped right breast lesion of intermediate to high signal intensity. $\mathbf{b}$ Axial T1WI, the lesion appeared of low signal intensity. c, d DWI and ADC map, the lesion appeared free on diffusion with a mean ADC value $=2 \times 10-3 \mathrm{~mm}^{2} / \mathrm{s}$. e Subtraction MR image, the lesion showed no significant enhancement. Pathological diagnosis revealed post-operative fibrosis and scar tissue

$0.76 \times 10-3 \mathrm{~mm}^{2} / \mathrm{s}$, mean ADC value for fat necrosis was $1.36 \times 10-3 \mathrm{~mm}^{2} / \mathrm{s}$, mean $\mathrm{ADC}$ value for postoperative seroma was $2.36 \times 10-3 \mathrm{~mm}^{2} / \mathrm{s}$, mean ADC value for post-operative scar was $1.73 \times 10-3 \mathrm{~mm}^{2} / \mathrm{s}$, and mean ADC value for infected seroma was $0.9 \times 10-$ $3 \mathrm{~mm}^{2} / \mathrm{s}$ (Table 2).

A cutoff $\mathrm{ADC}$ value of $1 \times 10-3 \mathrm{~mm}^{2} / \mathrm{s}$ for observer one had $80 \%$ sensitivity, $90.9 \%$ specificity, $66.7 \% \mathrm{PPV}$, 95.2\% NPV, and $88.9 \%$ accuracy in diagnosis of recurrent breast carcinoma. For observer two, a cutoff ADC value of $1.25 \times 10-3 \mathrm{~mm}^{2} / \mathrm{s}$ had sensitivity of $80 \%$, specificity of $88.6 \%$, PPV of $61.5 \%$, NPV of $95.2 \%$, and diagnostic accuracy of $87.03 \%$ in differentiating recurrent breast carcinoma from benign post-operative changes (Table 3) (Fig. 5).There was excellent agreement between both observers about the measured cutoff ADC value (intraclass correlation coefficient 0.948 , 95\% confidence interval 0.912-0.969).

Final diagnosis of unenhanced MRI studies (T1WI, T2WI, STIR, and DWI) of 110 female patients by both observers was recurrent breast carcinoma in 20 patients (18.1\%), fat necrosis in 34 patients (30.9\%), postoperative seroma in 46 patients $(41.8 \%)$, post-operative scar tissue in 8 patients (7.2\%), and normal study in 2 patients (1.8\%). There was excellent agreement between both observers about the final diagnosis of 110 patients by unenhanced MRI (Kappa $=1.00, P$ value $=0.001)$ (Table 4).

On comparing the final diagnosis by unenhanced MRI with DCE-MRI and pathological diagnosis, we found that 2 cases of infected seromas were falsely diagnosed as recurrent breast carcinoma. However, they were truly diagnosed by dynamic MRI. Two cases were falsely reported as normal study on unenhanced MRI; however, linear non-mass enhancement was observed on the two cases on dynamic MRI, and they were proved to have recurrent invasive duct carcinoma. Two cases were falsely diagnosed by both unenhanced MRI and dynamic MRI as fat necrosis, and pathological diagnosis revealed recurrent grade II invasive duct carcinoma. Otherwise, the final diagnosis of the remaining cases was similar on unenhanced MRI, dynamic MRI, and pathological diagnosis (Table 5). 
Table 1 Showed sensitivity, specificity, PPV, NPV, and accuracy of presence of fat signal intensity in differentiating fat necrosis from recurrent breast carcinoma

\begin{tabular}{llllll}
\hline & Sensitivity & Specificity & PPV & NPV & Accuracy \\
\hline Presence of fat signal intensity & $100 \%$ & $90.9 \%$ & $94.1 \%$ & $100 \%$ & $96.2 \%$ \\
\hline
\end{tabular}

Both observers found that unenhanced breast MRI had $81.8 \%$ sensitivity, $97.7 \%$ specificity, 90\% PPV, 95.5\% $\mathrm{NPV}$, and $94.5 \%$ diagnostic accuracy in differentiating recurrent breast carcinoma from benign post-operative changes. DCE-MRI had $90.9 \%$ sensitivity, $100 \%$ specificity, 100\% PPV, 97.7\% NPV, and 98.1\% diagnostic accuracy in differentiating recurrent breast carcinoma from benign post-operative changes (Table 6).

\section{Discussion}

The main findings in this study were that unenhanced breast MRI (based on analysis of lesion SI and measured ADC value) had high sensitivity, specificity, and diagnostic accuracy in detection of recurrent breast carcinoma and differentiating it from benign post-operative changes as fat necrosis and post-operative scar. However, there is still overlap in some cases as cases of infected seromas and some cases of recurrent breast carcinoma.

Fat necrosis is a common and challenging pitfall in interpreting $\mathrm{MR}$ images following breast conservative surgery. However, when it is adequately diagnosed, it can be categorized as BI-RADS 2 or BI-RADS 3 category. On MRI, the presence of fat SI within the lesion on unenhanced images is the most important diagnostic feature of fat necrosis [2]. Hassan et al. [10] studied the specific imaging features of fat necrosis and concluded that the presence of fat signal intensity within the lesion on unenhanced MR images had sensitivity of $98.04 \%$, specificity of $100 \%$, PPV of $100 \%$, and NPP of $96.88 \%$. Vasei et al. [3] stated that fat necrosis usually appeared isointense to the fat elsewhere in the breast, it appeared of high SI on T1WI and hypointense on STIR images when compared with the surrounding fat, and this is known as the black hole sign. This is concordant with our results where the presence of fat SI within the lesion had $100 \%$ sensitivity, $90.9 \%$ specificity, and $96.2 \%$ accuracy in differentiating fat necrosis from recurrent breast carcinoma.

On measuring ADC values for lesions included in this study, both observers found that the mean ADC value for recurrent breast carcinoma was $0.79 \times 10-3 \mathrm{~mm}^{2} / \mathrm{s}$ for observer 1 and $0.76 \times 10-3 \mathrm{~mm}^{2} / \mathrm{s}$ for observer 2 , and this is nearly similar to Guatelli et al. [11] who found that the mean ADC value for malignant breast tumors was $0.97 \times 10-3 \mathrm{~mm}^{2} / \mathrm{s}$; also, our results agreed with a study performed by Yilmaz et al. [8], and they found that the mean ADC value for malignant breast tumors was $0.884 \times 10-3 \mathrm{~mm}^{2} / \mathrm{s}$. Also, we matched with the study performed by Altay and his colleagues [12]who found that mean $\mathrm{ADC}$ value for malignant breast tumors was $0.96 \pm 0.25 \times 10-3 \mathrm{~mm}^{2} / \mathrm{s}$.

In this study, both observers found that the mean ADC value for recurrent breast carcinoma was lower than that of post-operative scar $\left(0.79 \times 10-3 \mathrm{~mm}^{2} / \mathrm{s}\right.$ for recurrent carcinoma versus $1.73 \times 10-3 \mathrm{~mm}^{2} / \mathrm{s}$ for postoperative scar) $(p<0.001)$, and this is in concordant with the study performed by Rinaldi et al. [13], and they stated that the average ADC value of recurrences was statistically lower than post-operative scar tissue $(p<$ 0.001). Also, our results matched with Abdulghaffara et al. [14] who stated that the mean ADC value of recurrent breast carcinoma $\left(\right.$ mean $=0.95 \times 10-3 \mathrm{~mm}^{2} / \mathrm{s}$ ) was significantly lower than that of scar tissue $($ mean $=1.66$ $\times 10-3 \mathrm{~mm}^{2} / \mathrm{s}$ ).

Regarding the mean ADC value of fat necrosis, we found that it was significantly higher than that of recurrent breast carcinoma. This is in agreement with Abdulghaffara et al. [14] who stated that the mean ADC value of fat necrosis was higher than that of recurrent breast carcinoma (mean ADC value $=1.41 \times 10-3 \mathrm{~mm}^{2} / \mathrm{s}$ for fat necrosis versus $0.95 \times 10-3 \mathrm{~mm}^{2} / \mathrm{s}$ for recurrent breast carcinoma). Hassan et al. (10) stated that adding

Table 2 Showed mean ADC value for different lesions included in the study by both observers

\begin{tabular}{|c|c|c|c|c|c|}
\hline & & \multicolumn{4}{|c|}{ ADC value } \\
\hline & & \multicolumn{2}{|c|}{ Observer 1} & \multicolumn{2}{|c|}{ Observer 2} \\
\hline & & $\overline{\text { Mean }}$ & $\pm \mathrm{SD}$ & $\overline{\text { Mean }}$ & $\pm \mathrm{SD}$ \\
\hline \multirow[t]{5}{*}{ Final diagnosis by biopsy } & Fat necrosis & 1.39 & .40 & 1.36 & .41 \\
\hline & Infected seroma & .90 & .00 & .90 & .00 \\
\hline & Post-operative scar & 1.73 & .24 & 1.73 & .21 \\
\hline & Post-operative seroma & 2.37 & .46 & 2.36 & .45 \\
\hline & Recurrent malignancy & .79 & .18 & .76 & .19 \\
\hline
\end{tabular}


Table 3 Showed the cutoff ADC value between recurrent breast carcinoma and benign post-operative changes by both observers

\begin{tabular}{lllllllll}
\hline ADC & AUC $(95 \% \mathrm{Cl})$ & $P$ Value & Cutoff point & Sensitivity (\%) & Specificity (\%) & PPV (\%) & NPV (\%) & Accuracy (\%) \\
\hline First observer & $0.899(0.811-0.986)$ & $<0.001$ & 1.0 & 80.0 & 90.9 & 66.7 & 95.2 & 88.9 \\
Second observer & $0.928(0.858-0.999)$ & $<0.001$ & 1.25 & 80.0 & 88.6 & 61.5 & 95.1 & 87.03
\end{tabular}

diffusion non-restriction to the presence of fat SI within the lesion could result in 100\% sensitivity and specificity in diagnosis of fat necrosis.

In this study, we had two cases of infected seroma: they showed diffusion restriction with a mean ADC value of $0.9 \times 10-3 \mathrm{~mm}^{2} / \mathrm{s}$. Study performed by DururSubasi [15]stated that infected cysts and abscess usually appeared restricted on diffusion and results in false positive diffusion MRI.

Detection of non-mass enhancement on DWI alone is still difficult. According to the BI-RADS lexicon, nonmass enhancement is an enhancement of an area that is not a mass, typically occurring in an area of fibroglandular tissue that appears as normal on unenhanced images [7]. Avendano et al. [16] performed a study to evaluate the diagnostic accuracy of DWI and ADC values in assessment of lesions presenting as non-mass enhancement on DCE-MRI and concluded that $31 \%$ of lesions presented as non-mass enhancement on dynamic MRI could not be adequately evaluated by DWI. On the basis of our unenhanced MR images, we missed 2 cases of recurrent breast carcinoma that presented as non-mass enhancement on dynamic MR images.

In this study, a cutoff ADC value of $1 \times 10-3 \mathrm{~mm}^{2} / \mathrm{s}$ for observer one had $80 \%$ sensitivity, $90.9 \%$ specificity, and $88.9 \%$ accuracy in diagnosis of recurrent breast carcinoma. For observer two, a cutoff ADC value of $1.25 \times$ $10-3 \mathrm{~mm}^{2} / \mathrm{s}$ had sensitivity of $80 \%$, specificity of $88.6 \%$, and diagnostic accuracy of $87.03 \%$ in differentiating recurrent breast carcinoma from benign post-operative changes. This is nearly similar to Guatelli et al. [11] who stated that a cutoff ADC value of $1.03 \times 10-3 \mathrm{~mm}^{2} / \mathrm{s}$ had specificity of $97.2 \%$ and diagnostic accuracy of $80.2 \%$ for differentiation between benign and malignant lesions. Also, our results are closely related to the results obtained by Yilmaz et al. (8), and they stated that

\section{ROC Curve}

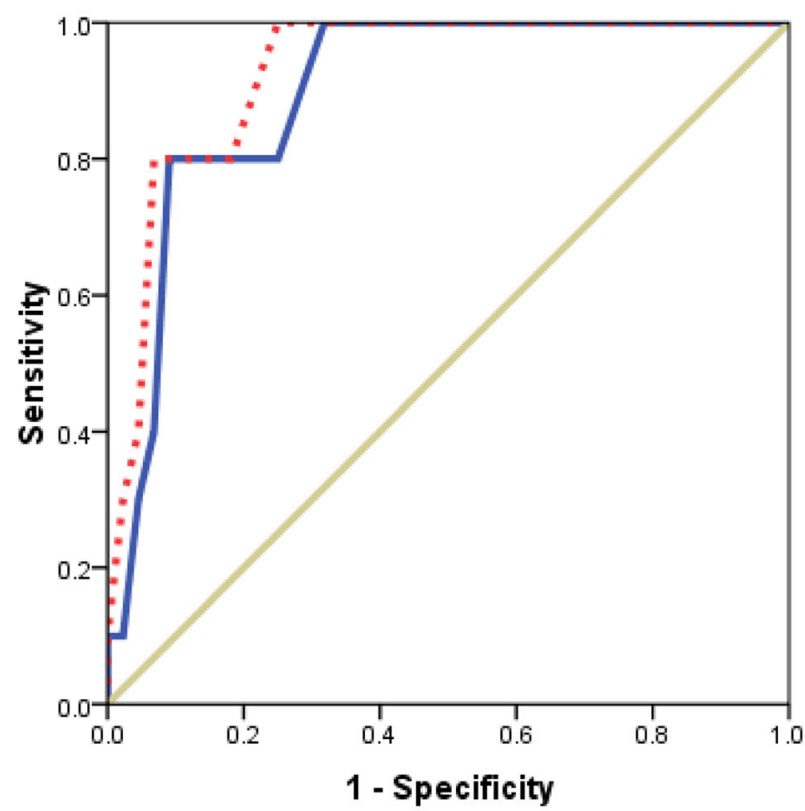

Source of the Curve

- ADC first observer

" " ADC second observer

- Reference Line

Diagonal segments are produced by ties.

Fig. 5 ROC curve for the cutoff ADC between recurrent breast carcinoma and benign post-operative changes by observer one and two. A cutoff ADC value of $1 \times 10-3 \mathrm{~mm}^{2} / \mathrm{s}$ for observer one had $80 \%$ sensitivity, $90.9 \%$ specificity, $66.7 \%$ PPV, 95.2\% NPV, and 88.9\% accuracy in diagnosis of recurrent breast carcinoma. For observer two, a cutoff ADC value of $1.25 \times 10-3 \mathrm{~mm}^{2} / \mathrm{s}$ had sensitivity of $80 \%$, specificity of $88.6 \%$, PPV of $61.5 \%$, NPV of $95.2 \%$, and diagnostic accuracy of $87.03 \%$ in differentiating recurrent breast carcinoma from benign post-operative changes 
Table 4 Showed final unenhanced MRI diagnosis by both observers and interobserver agreement

\begin{tabular}{|c|c|c|c|c|}
\hline & $\begin{array}{l}\text { Final unenhanced } \\
\text { MRI diagnosis by } \\
\text { observer } 1\end{array}$ & $\begin{array}{l}\text { Final unenhanced } \\
\text { MRI diagnosis by } \\
\text { observer } 2\end{array}$ & Kappa & $P$ \\
\hline $\begin{array}{l}\text { Recurrent } \\
\text { breast } \\
\text { carcinoma }\end{array}$ & $20(18.9 \%)$ & 20 (18.9\%) & 1.00 & $<0.001^{*}$ \\
\hline Fat necrosis & 32 (30.2\%) & $32(30.2 \%)$ & & \\
\hline $\begin{array}{l}\text { Post- } \\
\text { operative } \\
\text { seroma }\end{array}$ & 46 (43.4\%) & 46 (43.4\%) & & \\
\hline $\begin{array}{l}\text { Post- } \\
\text { operative } \\
\text { scar }\end{array}$ & $8(7.5 \%)$ & $8(7.5 \%)$ & & \\
\hline $\begin{array}{l}\text { Normal } \\
\text { study }\end{array}$ & $2(1.8 \%)$ & $2(1.8 \%)$ & & \\
\hline
\end{tabular}

$P$ probability

*Significance $<0.05$

Test used: Kappa

sensitivity and specificity of ADC were $88 \%$ and $87 \%$, respectively, at a cutoff value of $1.04 \times 10-3 \mathrm{~mm}^{2} / \mathrm{s}$. Altay and his colleagues [12] concluded that ADC value of 1.1 $\times 10-3 \mathrm{~mm}^{2} / \mathrm{s}$ as cutoff value for differentiation between malignant and benign breast lesions had a sensitivity of $91.3 \%$ and a specificity of $85.7 \%$.

On comparing the sensitivity and specificity of unenhanced MRI with that of DCE-MRI, we found that unenhanced MRI had $81.8 \%$ sensitivity and $97.7 \%$ specificity versus $90.9 \%$ sensitivity and $100 \%$ specificity for DCE-MRI. The sensitivity and specificity of unenhanced breast MRI were variable among previous studies [7, 9, 17 18], and Telegrafo et al. [17] evaluated the role of unenhanced MRI in detection and characterization of

Table $\mathbf{5}$ Showed comparison between the final diagnosis by unenhanced MRI by both observers, final diagnosis by dynamic MRI by both observers, and the final pathological diagnosis

\begin{tabular}{llll}
\hline & $\begin{array}{l}\text { Final unenhanced } \\
\text { MRI diagnosis by } \\
\text { both observers }\end{array}$ & $\begin{array}{l}\text { Final diagnosis by } \\
\text { dynamic MRI by } \\
\text { both observers }\end{array}$ & $\begin{array}{l}\text { Final } \\
\text { pathological } \\
\text { diagnosis }\end{array}$ \\
\hline $\begin{array}{l}\text { Recurrent } \\
\text { breast } \\
\text { carcinoma }\end{array}$ & $20(\mathbf{1 8 . 1 \% )}$ & $20(\mathbf{1 8 . 1 \% )}$ & $22(20 \%)$ \\
$\begin{array}{l}\text { Fat } \\
\text { necrosis }\end{array}$ & $34(30.9 \%)$ & $34(30.9 \%)$ & $32(29 \%)$ \\
$\begin{array}{l}\text { Post- } \\
\text { operative } \\
\text { seroma }\end{array}$ & $46(41.8 \%)$ & $46(41.8 \%)$ & $46(41.8 \%)$ \\
$\begin{array}{l}\text { Post- } \\
\text { operative } \\
\text { scar }\end{array}$ & $8(7.2 \%)$ & $8(7.2 \%)$ & $8(7.2 \%)$ \\
$\begin{array}{l}\text { Infected } \\
\text { seroma }\end{array}$ & $0(0 \%)$ & $2(1.8 \%)$ & $2(1.8 \%)$ \\
$\begin{array}{l}\text { Normal } \\
\text { Study }\end{array}$ & $2(1.8 \%)$ & $0(0 \%)$ & $0(0 \%)$ \\
\hline
\end{tabular}

Table 6 Showed sensitivity, specificity, PPV, NPV, and diagnostic accuracy of unenhanced MRI by both observers

\begin{tabular}{llllll}
\hline & Sensitivity & Specificity & PPV & NPV & Accuracy \\
\hline $\begin{array}{l}\text { Final diagnosis by } \\
\text { unenhanced MRI by } \\
\text { both observers }\end{array}$ & $\mathbf{8 1 . 8 \%}$ & $\mathbf{9 7 . 7 \%}$ & $\mathbf{9 0 . 0 \%}$ & $\mathbf{9 5 . 5 \%}$ & $\mathbf{9 4 . 5 \%}$ \\
$\begin{array}{l}\text { Final diagnosis by } \\
\text { dynamic MRI by } \\
\text { both observers }\end{array}$ & $\mathbf{9 0 . 9 \%}$ & $100 \%$ & $100 \%$ & $\mathbf{9 7 . 7 \%}$ & $\mathbf{9 8 . 1 \%}$ \\
\hline
\end{tabular}

breast cancer and concluded that it had sensitivity, specificity, diagnostic accuracy, PPV, and NPV values of 94\%, 79\%, 86\%, 79\%, and 94\%, respectively. Kul and his colleagues [18] evaluated the role of unenhanced MRI in characterization of breast masses having a low probability of being malignant (BI-RADS 3 and 4A) and concluded that it had 91\% specificity and 99\% negative predictive value (NPV) for detection of breast cancer. Trimboli et al. [7] studied the role of unenhanced MRI in detecting breast cancer and concluded that it had sensitivity of $78 \%$ and specificity of $90 \%$, and they attributed the low sensitivity of unenhanced MRI to its limited ability to detect DCIS and non-mass enhancement.

\section{Conclusion}

Finally, we concluded that unenhanced MRI including T1WI, T2WI, STIR, DWI, and ADC map had high sensitivity, specificity, and diagnostic accuracy in diagnosis of recurrent breast carcinoma and differentiating it from benign post-operative changes and so can be used in patients with contraindication for contrast material injection as patients with impaired renal functions.

\section{Abbreviations}

SD: Standard deviation; STIR: Short TI inversion recovery sequence; T1WI: T1weighted image; T2Wl: T2-weighted image; DWl: Diffusion-weighted image; ADC: Apparent diffusion coefficient; MRI: Magnetic resonance imaging; PPV: Positive predictive value; NPV: Negative predictive value; DCIS: Duct carcinoma in situ; FOV: Field of view; TI: Inversion time; CHESS: Chemical shift selective fat suppression; EPI: Echo planner imaging; TR: Repetition time; TE: Echo time; ms: Millisecond; mm: Millimeter; ICC: Interclass correlation coefficient; ROC: Receiver operating curve; BI-RADS: Breast imaging reporting and data system; AUC: Area under curve; Cl: Confidence interval;

MRM: Modified radical mastectomy; SI: Signal intensity

Acknowledgements

Not applicable.

\section{Authors' contributions}

ME revised the collected data and the manuscript. DM and ME analyzed the MRI images of all patients and measured the ADC value for each lesion separately. DM wrote the manuscript. ME performed the statistical analysis. All authors read and approved the final manuscript.

\section{Funding \\ No funding resources.}

Availability of data and materials

The datasets used and/or analyzed during the current study are available from the corresponding author on reasonable request. 


\section{Ethics approval and consent to participate}

The study was approved by our institution's ethics committee (Mansoura Faculty of Medicine Institutional Research Board) (ethics committee reference number is R.19.06.539), and all patients gave their written informed consent before inclusion in the study.

\section{Consent for publication}

All patients included in this research gave written informed consent to publish the data contained within this study. If the patient was less than 16 years old, deceased, or unconscious when consent for publication was requested, written informed consent for the publication of this data was given by their parent or legal guardian.

\section{Competing interests}

The authors declare that they have no competing interests.

Received: 18 January 2020 Accepted: 23 June 2020

Published online: 07 July 2020

\section{References}

1. Gutierrez R, Horst KC, Dirbas FM et al. Breast imaging following breast conservation therapy 2011. In: Dirbas FM, Scott-Conner CEH, editors. Breast surgical techniques and interdisciplinary management. USA: University of Washington; p. 975-995.

2. Drukteinis JS, Gombos EC, Chikarmane SRSA, Swami A, Birdwell RL (2012) MR imaging assessment of the breast after breast conservation therapy: distinguishing benign from malignant lesions. Radiographics 32:219-234. https://doi.org/10.1148/rg.321115016

3. Vasei N (2019) Shishegar A Ghalkhani F, and Darvishi M Fat necrosis in the nreast: a systematic review of clinical. Lipids Health Dis. 18:139. https://doi. org/10.1186/s12944-019-1078-4

4. Preda L, Villa G, Rizzo S, Bazzi L, Origgi D, Cassano E et al (2006) Magnetic resonance mammography in the evaluation of recurrence at the prior lumpectomy site after conservative surgery and radiotherapy. Breast Cancer Res. 8(5):53. https://doi.org/10.1186/bcr1600

5. Schnall MD, Blume J, Bluemke DA, DeAngelis GA, DeBruhl N, Harms S et al (2006) Diagnostic architectural and dynamic features at breast MR imaging: multicenter study. Radiology. 238(1):42-53. https://doi.org/10.1148/radiol. 2381042117

6. Orel G, Schnall MD (2001) MR imaging of the breast for detection, diagnosis, and staging of breast cancer. Radiology. 220:13-30. https://doi. org/10.1148/radiology.220.1.r01jl3113

7. Trimboli RM, Verardi N, Cartia F, Carbonaro LA, Sardanelli F (2014) Breast cancer detection using double reading of unenhanced MRI including T1weighted, T2-weighted, STIR, and diffusion-weighted imaging: a proof of concept study. American Journal of Roentgenology. 203:674-681. https:// doi.org/10.2214/AJR.13.11816

8. Yılmaz E, Sarı O, Yılmaz A, Ucar N, Aslan A, Inan I et al (2018) Diffusionweighted imaging for the discrimination of benign and malignant breast masses; utility of ADC and relative ADC. journal of the Belgian society of radiology 102(1):24. https://doi.org/10.5334/jbsr.1258

9. Amornsiripanitch N, Bickelhaupt S, Shin HJ, Dang M, Rahbar H, Pinker K et al (2019) Diffusion-weighted MRI for unenhanced breast cancer screening. Radiology. https://doi.org/10.1148/radiol.2019182789

10. Hassan H H M, El Abd A M, Abdel Bary A, Naguib N N N. Fat necrosis of the breast magnetic resonance imaging characteristics and pathologic correlation. Academic Radiology. 2018; 25 (8): 985- 992. DOl: https://doi.org/ 10.1016/j.acra.2017.12.019

11. Guatelli CS, Bitencourt AGV, Bueno de Toledo Osório CA, Graziano L, Araújo de Castro A, Alves de Souza J (2017) Can diffusion-weighted imaging add information in the evaluation of breast lesions considered suspicious on magnetic resonance imaging? Radiol Bras 50(5):1678-7099. https://doi.org/ 10.1590/0100-3984.2016.0089

12. Altay C, Balci P, Altay S, Karasu S, Saydam S, Canda T (2014) etal., Diffusionweighted MR imaging: role in the differential diagnosis of breast lesions. JBR-BTR. 97(4):211-216. https://doi.org/10.5334/jbr-btr.80

13. Rinaldi P, Giuliani M, Belli P, Costantini M, Romani M, Distefano D et al (2010) DWI in breast MRI: Role of ADC value to determine diagnosis between recurrent tumor and surgical scar in operated patients. European journal of radiology. 75(2):114-123. https://doi.org/10.1016/j. ejrad.2010.01.018
14. Abdulghaffara W, Magdy M (2014) Role of diffusion-weighted imaging and apparent diffusion coefficient in differentiating between local tumor recurrence and benign breast changes after breast conservative surgery. Global Journal of Medical research. 14(1):2249-4618

15. Durur-Subasi I (2019) DW-MRI of the breast: a pictorial review. Insights Imaging. 10:61. https://doi.org/10.1186/s13244-019-0745-3

16. Avendano D, Marino MA, Leithner D, Thakur S, Bernard-Davila B, Martinez DF et al (2019) Limited role of DWI with apparent diffusion coefficient mapping in breast lesions presenting as non-mass enhancement on dynamic contrast-enhanced MRI. Breast Cancer Res 21:136. https://doi.org/ 10.1186/s13058-019-1208-y

17. Telegafo M, Rella L, Stabile lanora AA, Angelelli G, Moschetta M (2015) Unenhanced breast MRI (STIR, T2-weighted TSE, DWIBS): an accurate and alternative strategy for detecting and differentiating breast lesions. Magn Reson Imaging. 33(8):951-955. https://doi.org/10.1016/j.mri.2015.06.002

18. Kul S, Oğuz S, Eyüboğlu İ, Kömürcüoğlu Ö (2015) Can unenhanced breast MRI be used to decrease negative biopsy rates? Diagn Interv Radiol. 21(4): 287-292. https://doi.org/10.5152/dir.2014.14333

\section{Publisher's Note}

Springer Nature remains neutral with regard to jurisdictional claims in published maps and institutional affiliations.

\section{Submit your manuscript to a SpringerOpen ${ }^{\circ}$ journal and benefit from:}

- Convenient online submission

- Rigorous peer review

- Open access: articles freely available online

- High visibility within the field

- Retaining the copyright to your article

Submit your next manuscript at $>$ springeropen.com 